The Geneva Papers on Risk and Insurance, 23 (No. 88, July 1998), 309-317

\title{
The Strategic Development of Insurance Markets: Some Reflections with Particular Focus on Commercial Risks and Risk Financing Innovations
}

\author{
by Walter B. Kielholz* and Kai-Uwe Schanz**
}

\section{Introduction}

The world is changing at a breathtaking pace. One major driving force is the accelerating globalisation of business and polities. Not surprisingly, the rules of the game are being redefined. The name of this game is "Facing the challenges of unprecedented global competition".

This competitive shock is not only affecting manufacturing companies but increasingly also the financial services sector in general, and the insurance industry in particular. Insurers, reinsurers and brokers are currently facing four challenges which are likely to have a crucial impact, not least on commercial insurance clients.

- The first challenge comes from the ongoing globalisation of risks, which is creating new client needs and requires innovative responses.

- At the same time, just like manufacturing companies, insurers are having to meet increasing demands from capital markets for higher returns on equity.

- Third, the deregulation of insurance terms and conditions and the dismantling of barriers to foreign competition is leading to lower margins and to higher volatility of underwriting results.

- And last but not least, state supervisory authorities and "implicit" regulators such as rating agencies are getting increasingly concerned about insurers' security. Accordingly, they are going to start putting more emphasis on solvency.

* Walter B. Kielholz, Chief Executive Officer, Swiss Re Group, Zurich.

** Kai-Uwe Schanz, Senior Economist, Swiss Re Economic Research, Zurich. 
Figure 1: Strategic challenges facing the insurance industry

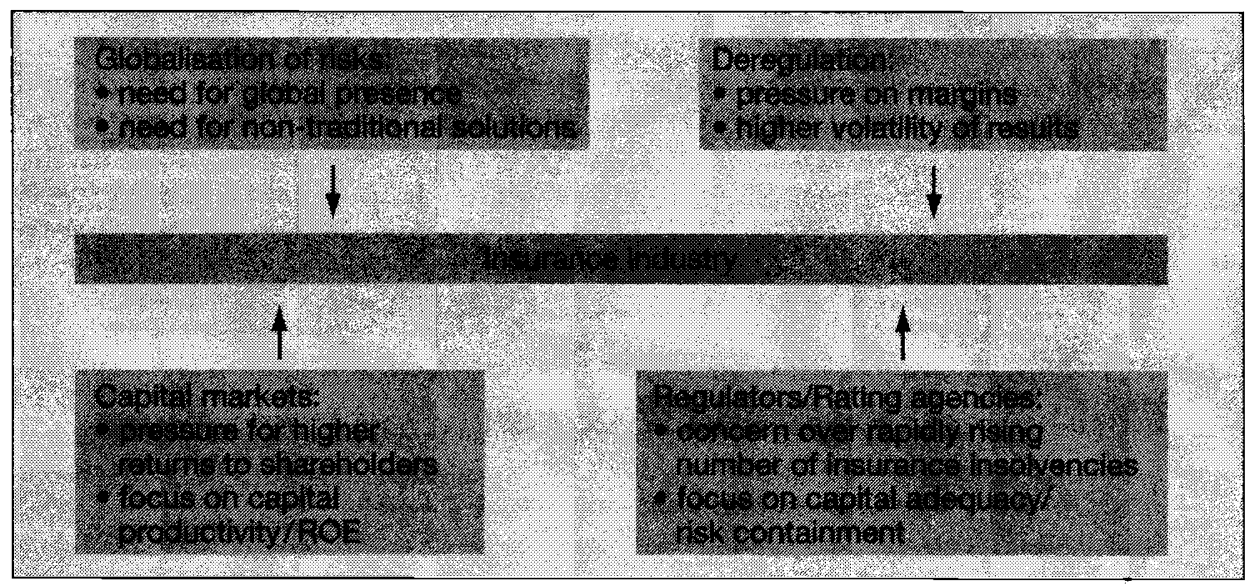

The globalisation of world markets is probably one of today's most pronounced phenomena. Its economic dimension implies that international trade and investment flows are growing substantially faster than national gross domestic products. The world economy is no longer restricted to the so-called "Triad" of North America, Western Europe and Japan. Emerging markets in Asia, Latin America and Eastern Europe are rapidly being integrated into the global system of trade and investment. The mounting interdependence via trade links and financial markets is reflected in the fact that recent regional crises in South East and East Asia have spilled over into other regions.

Corporate managers are very familiar with the phenomenon of globalisation. But in the insurance industry, too, globalisation is increasingly becoming a top issue. Many risks are much more interdependent now than they were in the past. One striking example is business interruption. With globally linked value added chains, a flood catastrophe in China could bring certain business operations in Europe to a standstill. For insurers confined to national or regional markets, it is virtually impossible to assess these globally linked risks properly.

A second challenge is that insurance companies' shareholders are demanding higher returns on equity. This is due to the global integration of capital markets, which no longer allows "islands" of inadequate rates of return to survive. Furthermore, investors' higher expectations of returns are the result of higher profit volatility due to deregulation.

Deregulation is the third challenge. In many European, Asian and Latin American countries the insurance industry was subjected to special treatment by governments with prices, terms and conditions strictly regulated. Frequently, foreign providers were simply denied access to domestic markets. Not surprisingly, the mechanisms of supply and demand did not work properly. In the meantime things have changed fundamentally. In Europe, the process of deregulation and liberalisation is well under way'. In Japan comparable reforms are scheduled to be launched soon.

${ }^{1}$ Cf. Swiss Re (1996) 
The example of the European Union deserves particular attention. In 1990, commercial insurance of large risks was first exposed to freedom of services and home country control. Personal lines followed suit in 1994, with the greatest impact being in the field of motor insurance.

Against this background, commercial insurers are - in terms of experience - far ahead of personal lines insurers and are fairly familiar with the most striking effect of deregulation: margins coming under pressure. At the same time, the volatility of underwriting results is increasing. Lower and more volatile profits are of course unpopular with shareholders and their advisors, the financial analysts.

As rates, terms and conditions are no longer subject to prior government approval or market consensus, competition over prices is intensifying sharply. All European commercial insurers have had this experience. Greater vulnerability of the less well or too aggressively managed companies is the logical consequence. As a result, state regulators will have to think much harder about how they can reliably assess whether an insurance company's capital endowment is adequate. And rating agencies will be an important factor well beyond the borders of the US and the UK.

This is the background of a fourth challenge: Insurers have to perform a delicate balancing act. On the one hand, shareholders are demanding higher returns. On the other, regulators, rating agencies and last but not least the informed insurance buyers are pressing for more security, thus exposing insurers to the threat of eroding returns on equity. This leads to what Salomon Brothers have called the "ROE squeeze"2.

\section{Opportunities and Threats for Commercial Insurance Clients}

The following section is devoted to assessing the likely impact of these challenges on corporate insurance clients - both in terms of opportunities and in terms of threats. There is no doubt that the opportunities will outweigh the threats for those corporate risk managers and financial officers who understand the major implications of the new rules of the game.

Deregulation and liberalisation are catalysts to more efficient and innovative markets. Flexibility in terms of prices and conditions spurs competition. The same is true of new foreign players emerging in hitherto protected domestic insurance markets. Corporate clients are expected to benefit in various respects.

First, clients are profiting from more innovative and more flexible insurance products which come under the heading 'Alternative Risk Transfer' (ART). These solutions may offer integrated coverage not only for multiple years but also for several lines of business, including even non-insurance risks. ART covers tend to be more cost-effective than traditional insurance or reinsurance. Terms and conditions generally reflect the client's individual loss experience and therefore provide some insulation from insurance market cycles. So ART is part of a general trend in insurance business towards tailor-made and customised solutions with less emphasis on collective risk sharing.

${ }^{2}$ Cf. Salomon Brothers (1997). 
Second, clients enjoy markedly improved services from insurers, reinsurers and brokers. Under pressure from intensifying competition, insurance providers are increasingly trying to market themselves as expert risk advisors, not only with superior loss prevention and claims settlement skills but also with outstanding know-how on the financial engineering of risk solutions.

Third, in order to gain a competitive advantage insurers and reinsurers are systematically looking for opportunities to save on transaction costs. The process of risk intermediation is streamlined, for example by captives directly accessing reinsurance markets or commercial insurers bypassing brokers. This trend is known as "risk disintermediation". Clients are thus likely to profit from a leaner value chain in commercial business. Apart from cheaper coverage, corporate clients also benefit from the fact that those who finally absorb and/or finance risks are moving closer to clients' exposures. This enables insurers and reinsurers to gain a better understanding of clients' needs.

In order to paint a balanced picture, some risks and threats resulting from the competitive shock in commercial insurance business have to be addressed as well. For corporate clients, increasing credit risks associated with insurance companies are likely to be of utmost concern.

Since 1978, more than 650 non-life insurance companies around the world have gone bankrupt. Here, it is the most competitive markets which led the field. The US and UK accounted for no less than 73 percent of the insolvencies recorded ${ }^{3}$. The number of insolvencies in these markets has grown alarmingly large for an industry which sells security and promises future payment. This development does not augur well for the security of the markets now in the process of deregulation.

It is therefore not surprising that, in the UK for example, financial security is already the most important factor when corporate risk managers choose an international insurer. In continental Europe, too, risk managers will become more aware of financial security when it comes to purchasing commercial insurance.

\section{Wave of Consolidation in the Insurance and Brokerage Industries}

Apart from deregulation and globalisation, the term "consolidation" is at present probably most frequently used in insurance, reinsurance and brokerage. Accelerating consolidation is part of the industry's response to the new challenges and client needs outlined above.

The process of consolidation in insurance, reinsurance and brokerage is a multifaceted phenomenon: It entails not only mergers, acquisitions and insolvencies but also large-scale corporate restructuring aimed at focussing on core competences.

In Europe we recently witnessed a spate of mega-mergers in primary insurance:

In February 1998, British Insurers Commercial Union and General Accident decided to merge. The new company will tank as Britain's second biggest insurer and Europe's ninth largest.

${ }^{3}$ Cf. Swiss Re (1995). 
In December 1997 the German market leader Allianz announced the acquisition of Assurance Générales de France (AGF). By making this move, Allianz will not only substantially enhance its position in France, Belgium and Spain but also - in terms of premium income - achieve the top position in global insurance.

In October 1997 Zurich Insurance Group and the financial services group of BAT Industries agreed to merge. This deal will create Europe's third-largest insurance group. The reasoning behind this transaction is clearly dominated by considerations regarding personal lines and asset management.

The second-largest German insurer came into being when Victoria and HamburgMannheimer merged in July 1997 to form the new Ergo Insurance Group.

In November 1996 Axa Insurance Group acquired Union des Assurances de Paris (UAP), replacing (temporarily) Allianz as Europe's leading insurance group and becoming the second-largest insurer in the world.

And finally, in May 1996 the British property \& casualty insurers Royal Insurance and Sun Alliance joined forces to form Britain's largest general insurer. By combining their resources, both companies not only hoped to benefit from substantial savings in administration and acquisition costs but also to enhance their position as global players in commercial insurance. And local presence around the globe is one of the key client requirements that commercial insurers increasingly have to meet.

Even more spectacular consolidation moves occured in global reinsurance. In this business, diversification is of paramount importance. Against this backdrop, the globalisation strategies of the world's leading reinsurers not only serve the purpose of enhanced market presence. Above all, reinsurers are aiming at better diversification across regions and lines of business. Improvements in diversification imply that the reinsurer needs less risk capital and benefits from lower capital costs.

Figure 2: Development of Top 4 reinsurers' market share

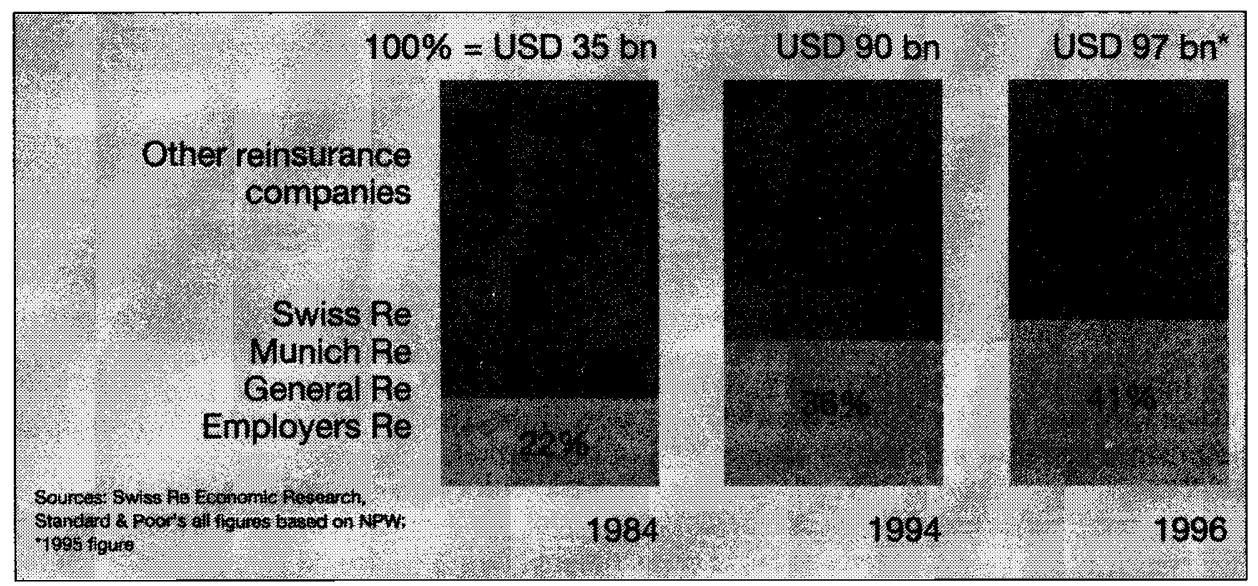


Not surprisingly, diversification was a prime driver in reinsurance consolidation over the past four years: US reinsurers General Re and Employers Re strengthened their international position through the acquisition of Cologne $\mathrm{Re}$ and Frankona/Aachen $\mathrm{Re}$ respectively. Munich $\mathrm{Re}$ acquired American Re, thus substantially enhancing its US presence. And Swiss Re purchased the British reinsurer Mercantile \& General Re, thus becoming the world's leading provider in the promising field of life $\&$ health reinsurance.

This process of consolidation had a major impact on the distribution of reinsurance market shares. The Top 4 increased their shares substantially and now account for more than $40 \%$ of global reinsurance premiums.

Finally, an unprecedented wave of consolidation swept over global brokerage. In 1996 and 1997, six of the world's Top 20 brokers were snapped up by larger competitors. Aon Group alone acquired four of them: Alexander \& Alexander, Bain Hogg, Minet and Jauch \& Hubener. The two remaining companies, Johnson \& Higgins and CECAR, were absorbed by Marsh \& McLennan ${ }^{4}$.

The trend towards risk disintermediation is forcing brokers to redefine their role. The purely transactional function no longer seems a guarantee of long-term survival. Instead, many brokers are increasingly relying on creating value by providing risk advisory services including innovative areas such as captive management and financial engineering. The successful implementation of this strategy frequently requires the pooling of skills and resources, substantial investments in information technology and a local presence around the globe 5 .

Figure 3: Consolidation in global brokerage

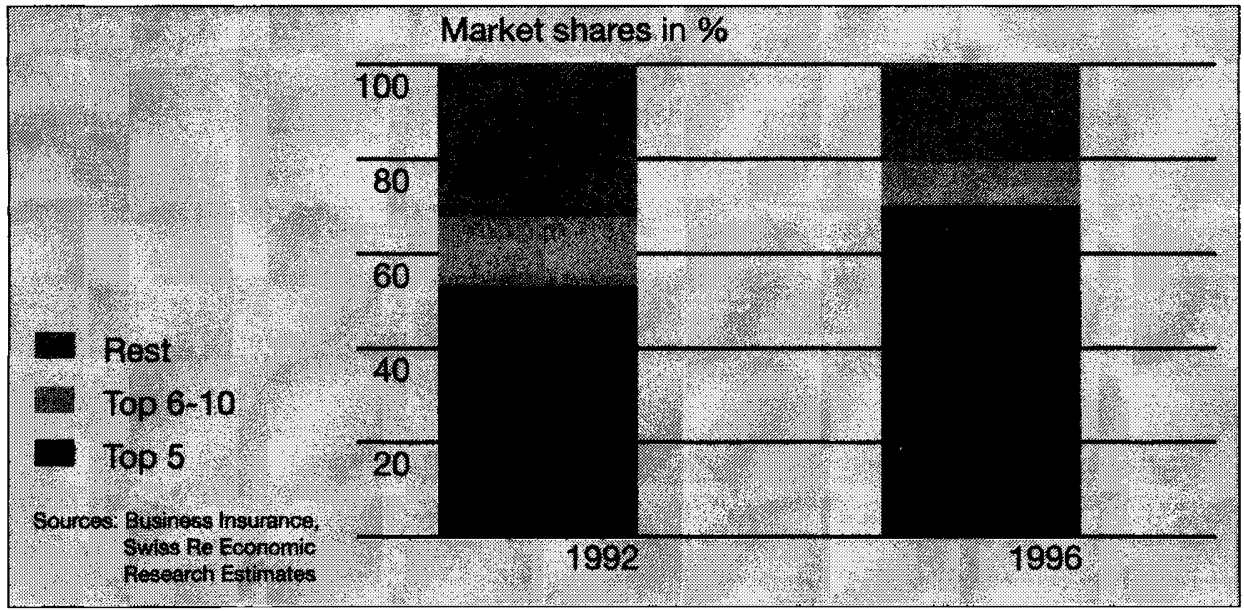

As a result of that sweeping consolidation, the 1996 revenues of the ten largest brokers are just slightly behind the 1995 revenues of the Top 20 . The Top 5 enhanced their dominance and now account for almost $70 \%$ of the market.

${ }^{4}$ Cf. Business Insurance (1997).

${ }^{5}$ Cf. Brogden (1996). 


\section{Alternative Risk Transfer - The Spearhead of Innovation}

New challenges require imaginative solutions. The rapid evolution of non-traditional risk transfer and risk financing techniques conveys a particularly interesting lesson. Fiercer competition in the insurers', reinsurers' and brokers' business environment in conjunction with changing client needs have triggered an unprecedented wave of innovation - to the particular benefit of corporate clients.

In the eighties, corporate risk managers were faced with severe problems such as a lack of adequate insurance coverage and the increasing volatility of insurance prices. In other words, the insurance industry has not always succeeded in performing its core function: That of exchanging a certain but budgetable loss (the insurance premium) for a loss which is potentially devastating. Many companies' logical response was increased reliance on self-insurance or the establishment of captives. In the meantime, these devices have become rather mainstream.

More exciting are recent developments such as the emergence of blended multi-year, multi-line covers and the tapping of capital markets as ultimate bearers of risk. This trend basically reflects the increasingly global business environment and exposures.

Figure 4: Illustration of a multi-year, multi-line cover

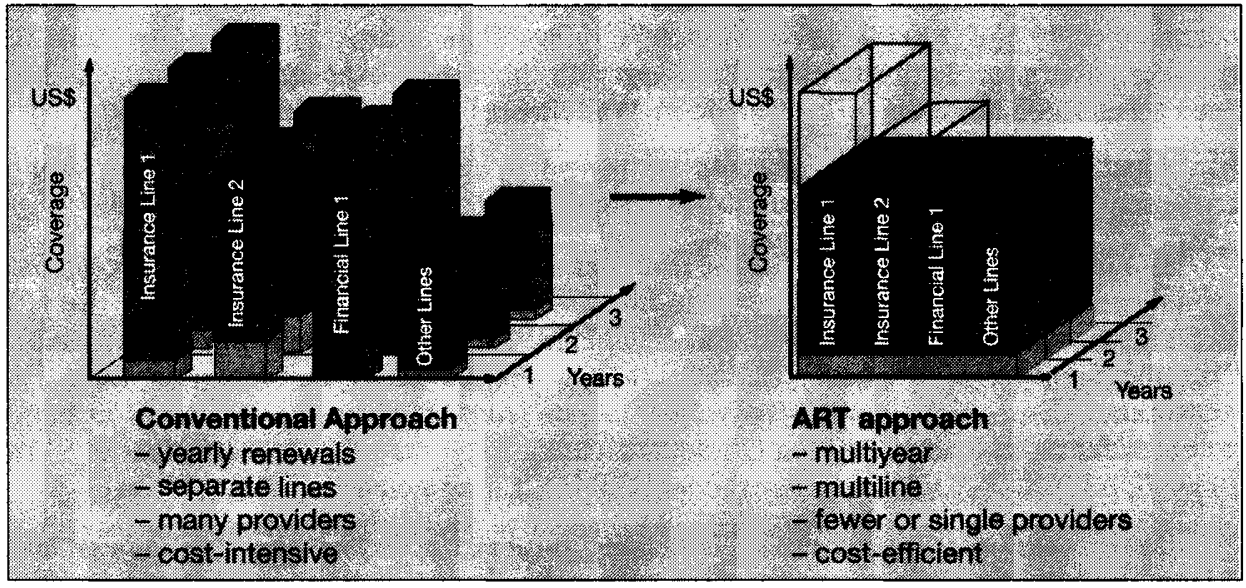

As a rule, traditional commercial insurance covers are one-year, one-line arrangements subject to annual renegotiation largely based on the loss experience of the market as a whole rather than the individual client. An increasing number of clients no longer consider this satisfactory. Instead they seek alternative forms of coverage which extend over several years, encompass multiple lines of business, reward positive individual loss experience and blend the client's self retention, risk financing elements and traditional insurance/reinsurance solutions into one package.

Blended multi-year, multi-line covers provide the client with various striking economic benefits: They take a flexible approach to the client's individual risk profile, which is made up of heterogeneous elements such as (1) easily predictable high-frequency, 
low-severity losses, (2) losses that may be reliably predicted over a period of several years and (3) low-frequency/high-severity exposures that threaten a company's very existence and require some form of risk transfer device.

All these elements are priced specifically, according to the nature of the individual exposure, so that the client only buys what he really needs. This makes blended covers particularly cost-effective ${ }^{6}$.

Because of their design features, such integrated solutions can cover even risks that are traditionally considered uninsurable. By packaging different, not perfectly correlated client exposures, internal or external hedges may be used. Thus in addition to traditional insurance risks such as property catastrophe, products liability and workers' compensation, other exposures such as political, financial or even business risks may be handled.

These innovative solutions help clients develop a holistic risk management approach with simultaneous consideration of both sides of the balance sheet. The ultimate objective is to enhance shareholder value by reliably avoiding large hits to earnings which may arise not only from hazard but also from financial and business-related exposures.

Another innovation, which admittedly is still in its infancy, is based on transferring insurance risks to capital markets. Some of the largest risks in the world - a massive earthquake in California or Tokyo - are difficult to insure and reinsure in terms of adequate cover and reasonable cost. Insurers, reinsurers and brokers have started to look for alternative sources of risk capital to cope with the largest exposures. This process has been accelerated by similar efforts made by Wall Street firms like Goldman Sachs.

Ideally, these gigantic risks could be placed in the capital market. This market's attraction for the insurance industry lies in its enormous financial capacity.

Compared with the capacity of the traditional insurance and reinsurance markets, the capitalisation of the financial markets is impressive: the assets being traded in the US alone are worth more than 20,000 billion US dollars. This is about one hundred times more than the equity capital of all US insurers and one thousand times greater than US reinsurance companies' equity. Daily fluctuations in value - averaging about 70 basis points or far more than 100 billion US dollars - are greater than the estimated loss of 50 to 100 billion US dollars which the worst conceivable Californian earthquake could cause ${ }^{7}$.

These risks may be placed by launching futures on catastrophe loss indices and related options. An alternative is to place such risks directly with investors in the form of securities which yield according to insurance-related losses. Recent developments are encouraging, particularly in the area of securitisation. For example, in November 1997, Swiss Re and Goldman Sachs successfully completed the first transaction to securitise Japanese earthquake risk. That deal provided Tokio Marine \& Fire Insurance Co. with additional earthquake risk coverage of USD 90 million.

The attraction for the investor lies in the fact that natural catastrophe volatilities are almost uncorrelated with stock market volatility; 'almost', because while we are pretty

${ }^{6}$ Cf. Swiss Re (1997) and Schanz (1997).

${ }^{7}$ Cf. Kielholz / Durer (1997). 
certain that Wall Street events cannot trigger an earthquake, we are not quite sure as to the other way round...

\section{Conclusion}

In the insurance industry there is an overriding trend towards tailor-made solutions, whereas standardized products are losing importance. This trend is largely due to bigger and more complex risks which arise as the globalisation of markets proceeds. Corporate clients, in particular, seek risk management solutions which go far beyond the traditional borders of insurability. In order to be able to absorb and to handle larger insurance risks, but also financial and business risks, insurers, reinsurers and brokers are forming bigger entities. But this process of consolidation is only one part of the answer. The other, and probably the more important one, is the development of 'Alternative Risk Transfer' techniques with the tapping of capital markets as final risk absorbers being the most revolutionary move.

\section{REFERENCES}

BROGDEN, Andrew, "Global Commercial Insurance Broking”, FT Financial Publishing, London, 1996.

BUSINESS INSURANCE, 26th Annual Agent/Broker Profiles Issue, July 21, 1997.

KELLENBERGER, Rudolf, SCHANZ, Kai-Uwe, "Deregulierung und Marktöffnung in der Assekuranz - Neue Spielregeln für Europas Versicherungswirtschaft", Neue Zürcher Zeitung, No. 20, 1997.

KIELHOLZ, Walter B., DURRER, Alex, "Insurance derivatives and securitization: New hedging perspectives for the US cat insurance market", The GENEVA PAPERS on Risk and Insurance Issues and Practice, pp. 3-16, No. 82, January 1997.

SALOMON BROTHERS, "Global Insurance - Creating shareholder value in a consolidating industry", 1997.

SCHANZ, Kai-Uwe, "Initiation in ART", The Review, pp. 75-78, September 1997.

SCHANZ, Kai-Uwe, "Blending Offers Protection Against Volatility", National Underwriter, P/C Insurance Edition, September 1, 1997.

SWISS RE, "MACRO - A holistic approach to multiple risks", 1997.

SWISS RE, sigma No. 7/1996, "Deregulation and liberalization of market access: the European insurance industry on the threshold of a new era in competition".

SWISS RE, sigma No. 7/1995, "Development of insolvencies and the importance of security in the insurance industry". 